\title{
Will Forensic Psychiatry survive DSM-5?
}

\author{
S Kaliski \\ Forensic Mental Health Services, Western Cape, Department of Psychiatry, University of Cape Town, Cape Town, South Africa
}

The fifth edition of the Diagnostic and Statistical Manual of Mental Distorders (DSM-5) will be released in 2013, and if, as anticipated, introduces wide ranging changes, may not only wipe out large swathes of accepted research but will reinforce the already prevalent view that psychiatric diagnoses are mostly arbitrary and have questionable validity. No other medical speciality suffers this indignity. The President of the American Psychiatric Association (APA) recently pointed out that the original purpose of DSM was to improve interrater reliability in psychiatric diagnosis, and although the original intention was to stimulate research into establishing their validity DSM diagnoses have actually become reified (as if they were real entities). ${ }^{1}$ In the bad old days psychiatric diagnoses were often idiosyncratic and localised either to a country, or theorist. Even nowadays some of those curious entities still bubble up into our courts, such as the quaint 'catathymic crisis' that is often produced to explain that a defendant lost his temper, because he simply couldn't take it (whatever 'it' was) anymore.

The use of psychiatric diagnoses in juridical settings has always been problematic. Our Criminal Procedure Act (No 51 of 1977) requires that 'mental disorder', 'mental defect' or 'any other reason' (section 78) ${ }^{2}$ be present before issues of triability or criminal responsibility are considered. Unfortunately none of these terms is defined properly, and the assessing clinicians can theoretically use any diagnosis to excuse an accused's behaviour. DSM-IV TR, the latest incarnation of the series, specifically warned against the use of its categories for legal purposes, because diagnostic labels per se do not really inform about issues of impairment or competence. ${ }^{2}$ Notwithstanding this injunction the courts have routinely relied on DSM diagnoses, often to decide on landmark cases. ${ }^{3}$ In SA, for example, dissociative disorders have successfully been invoked to support the defence of nonpathological incapacity. ${ }^{4}$ Similarly pejorative diagnoses have been used to deny custody of children, to obtain pensions, monetary compensation, and to avoid working

All forensic assessments, therefore, consist of value judgements based on demonstrable pathology. If the latter is not valid then the former is of little use. DSM's prime purpose is to ensure that we all make the same diagnoses consistently, almost regardless of their validity (to achieve clinical utility), whereas juridical agencies rely on the truthfulness (i.e. validity) of those diagnoses (i.e. forensic utility). If our discipline continually revises its classification system the courts may respond by suspending their trust in our opinions, especially if important precedents will have to be disregarded because the disorders they then accepted as excuses are now declared obsolete at a stroke.

Correspondence

Prof S Kaliski

email: Sean.Kaliski@uct.ac.za

\section{What changes can we anticipate?}

The current framers of DSM-5 have skilfully allowed only glimpses of the changes this version may wreak on our profession. In comparison the Iranian nuclear programme appears blatantly transparent. But, for our purposes two broad and relevant changes may be important. First, the categorical classification scheme will be modified to allow for disorders to be described as dimensional entities. ${ }^{5}$ Secondly, as expected, new disorders have been proposed, some of which seem to be an attempt to create waystation disorders that are both dimensional and categorical, such as the Attenuated Psychotic Symptoms Syndrome. ${ }^{6}$

\section{Forensic utility and the continua of diagnoses}

In truth psychiatry has always been bedevilled by arguments over whether its disorders can be collected into discrete categories, or be regarded as entities that flow into each other along a continuum. What complicated this debate was the realisation that the entity 'mental illness' could not easily be differentiated clearly from 'mental health'. ' Increasingly there is evidence that most psychiatric symptoms, including hallucinations and delusions, occur in the general population at unexpected rates, without necessarily causing distress or impairment.

Not surprisingly, previous editions of DSM plumped for the categorical approach. Clinicians could now use the manual like a recipe book, even though the DSM itself warned against this approach. Symptoms could be ticked off, and as long as their numbers exceeded an arbitrary threshold, and somehow caused distress or impaired function, a definite diagnosis could be offered. Even though this was a fiction the courts rejoiced in the assessments mental health practitioners offered as, at the least, they offered the illusion of certainties that they could use to make difficult decisions.

Nevertheless the issue continues to nag at the profession. Research seemed to confirm that there is probably a continuum of the psychoses, that now extends from so-called prodromal states, to schizophrenia, and then with detours via schizoaffective disorders to bipolar mood disorders. Other areas introduced spectrum disorders, such as the OCD-spectrum. And increasingly clinicians were resorting to using the NOS categories, and accepted that up to $60 \%$ of cases attracted a clutch of co-morbid diagnoses., 1,7,8 Logically, then, a dimensional approach has stronger clinical utility, and probably is consonant with our current deep nosological uncertainties.

But this is terrible news for forensic mental health practitioners. I anticipate that many cases may degenerate into arguments over severity, and, therefore, whether the legal threshold for 'mental disorder' has been crossed. One can now be a touch psychotic and a little bit personality disordered. Using the criteria that the person must exhibit marked distress or impairment in function 
always begs the question in the forensic arena, as often the circumstances that led to the commission of a crime involved distress and poor functioning.

\section{What about new disorders?}

Every edition of DSM introduces new diagnoses, often eliminates a few established categories (such as homosexuality), and sometimes includes putative diagnoses for consideration (that often are then not included in future editions, such as the erstwhile 'self defeating personality disorder'). Apart from advertising psychiatry's ongoing nosological crisis this does cause some disarray where certainty of diagnosis is important. Not only the courts, which rely greatly on precedents, but also insurance companies and most employers depend on diagnoses that are unchangeable. The latter agencies allow for claimants to be declared permanently disabled on psychiatric grounds, and may find themselves paying pensions to claimants who no longer have a valid diagnosis, or worse still, have to begin considering applications from those who now suffer from a new disorder. For example, there are now proposals that Internet Addiction be considered to be a disorder, based on its similarity to other compulsive-impulsive disorders, and on its impact on public health. ${ }^{9}$ Presumably this now pathologises a new cohort of internet enthusiasts, who spend excessive time online such that they are unable to function properly. It is not fanciful, then, to postulate that psychiatrists will declare some of these to be treatment resistant (and therefore entitled to benefits for life or until the internet implodes), but also in concert with astute lawyers use this as an excuse for criminal behaviour.

But there are proposals for the paraphilias that possibly pose grave consequences for the criminal justice system. In the first instance is a proposal to distinguish between paraphilias that are to be considered to be non-disordered sexual variations, from paraphilic disorders whose diagnosis will depend on the harm they cause. Secondly, the diagnosis of 'disorder' will depend on the number of sexual victims, probably at least 2 or 3, i.e. a socalled objective behavioural criterion that almost always will be a crime. ${ }^{10}$ At first glance this appears to be an acceptance that variations in sexual desire and practice can be regarded normal unless they are harmful, which appears to provide ready excuses for most sexual offenders. This may encourage the courts to refer recidivistic sexual offenders for treatment, which may actually be preventive detention, rather than sentencing them. What are the framers of DSM thinking?

But it gets worse. One of the proposed new disorders is paraphilic coercive disorder, by which the 'sufferer' is recurrently aroused by forcing others to engage in sexual acts. This is surely converting rape, a terrible offence, into a psychiatric illness. Apparently the occurrence of serial rape alone will not qualify for the diagnosis, as the perpetrator will have to display uncontrollable deviant urges and fantasies that have manifested in other contexts or situations as well. ${ }^{11}$ The notion that our courts will easily distinguish between serial rapists that are just antisocial from those who apparently have a diagnosis and are impaired is fanciful. What exactly is the difference between an urge that craves expression and that which will not be denied?

Another fascinating proposal is to expand the pedophilia category to pedohebephilia. The core characteristic of hebephilia is recurrent sexual arousal by pubescent children, as opposed to that for pedophilia, which is concerned with prepubescent children. In effect this extends the paedophilia category from concern with children in Tanner's Stage 1 through to Tanner's Stages 3 and 4. The rationale for this is not clear, as it probably only extends the ages of interest from around 12 to 15 years old. ${ }^{8}$ I am not sure how this will play out in our courts, but I suspect that many more men caught for statutory rape with mature looking girls may escape imprisonment on condition that they submit to treatment.

So it comes to this: we will have to accept that more sexual offenders suffer from paraphilic urges that lead to impairment of volition, and consequently to sexual offending. In our law that may theoretically satisfy the criterion of not being able 'to act in accordance of an appreciation of wrongfulness' in section 78 of the Criminal Procedure Act. Such individuals may have to be certified as state patients. Will we be compelled to treat a burgeoning group of patients whom we do not really believe are disordered?

\section{What are we to do?}

Batten the hatches, rough seas are ahead. Our difficulties will not really be due to an inability to deal with the conceptual challenges these changes may demand, but will most likely originate from countering their use by colleagues, some of whom can be somewhat cynical in their use of psychiatric labels in attempting to divert their clients away from the clutches of the correctional services, or to persuade companies to pay generous compensations. The forensic mental health fraternity will therefore have to produce consensus positions on how these changes can satisfy the requirements of forensic utility. Some good may come of this if it encourages us as a profession to reflect and deal generally with how and why we use psychiatric diagnoses.

\section{References}

1. Bernstein C. Meta-structure in DSM-5 process. Psychiatric News 201 1; 46(5):7-29.

2. American Psychiatric Association. Diagnostic and Statistical Manual of Mental Disorders.Fourth Edition. Text Revised. Washington, DC:

American Psychiatric Association, 2000.

3. Slovenko R. The DSM in litigation and legislation. Journal of the American Academy of Psychiatry and the Law 2011; 39:6-11.

4. Louw R. Principles of criminal law: Pathological and non-pathological incapacity. In: Kaliski SZ, editor. Psycholegal Assessment in South Africa. Cape Town: Oxford University Press, 2006: 34-57.

5. Dimensional approaches in diagnostic classification. Refining the research agenda for DSM-V. Arlington, Virginia: American Psychiatric Association, 2008.

6. Woods SW, Walsh BC, Saksa JR, McGlashan TH. The case for including Attenuated Psychotic Symptoms Syndrome in DSM-5 as a psychosis risk syndrome. Schizophr Res 2010; 123((2-3)):199-207.

7. Jablensky A. Boundaries of mental disorders. Curr Opin Psychiatry 2005; 18:653-658.

8. Frances A, First MB. Hebephilia is not a mental disorder in DSM-IV-TR and should not become one in DSM-5. Journal of the American Academy of Psychiatry and the Law 201 1; 39:78-85.

9. Block JJ. Issues for DSM-V: Internet addiction. Am J Psychiatry 2008; 165(3):306-307.

10. Wakefield JC. DSM-5 proposed diagnostic criteria for sexual paraphilias: Tensions between diagnostic validity and forensic utility. International Journal of Law and Psychiatry 201 1; 34:195-209.

11. First MB, Halon RL. Use of DSM paraphilia diagnoses in sexually violent predator commitment cases. Journal of the American Academy of Psychiatry and the Law 201 1; 36:443-454. 